\title{
The Influence of Motivation on Secondary School Students' Performance in English Language
}

\author{
GILMAN J. NYAMUBI \\ Assistant Lecturer in Education, Iringa Lniversity College
}

\begin{abstract}
This paper attempts to underscore the influence of motivation on secondary school students' performance in English language. It examines how learning of English is shaped by students' academic and career aspirations. Thus, students' English language background and their exposure to the language as well as their perceptions of the factors that motivate them to learn English language are explored. It discloses that students use English language most often when they are at the school environment than home. Furthermore, the paper explains that students' performance in English language is determined by the time when they were exposed to the language, hence the need for students to learn English in their early years of study and to use the language regularly for better performance. It has been clearly pointed out that students in Tanzanian secondary schools are both instrumentally and integrativelly motivated to learn English language, which helped them to further their goals such as academic excellence and employment prospects. The paper ends by emphasizing that care should be exercised in any attempt to change English as the medium of instruction in secondary schools capitalizing on the learners' strong motivations for learning the language.
\end{abstract}

\section{BACKGROUND}

English language in all public primary schools and secondary schools in Tanzania is taught as a language, from class one onwards. It is also used as the medium of instruction in the education system from secondary school to tertiary level. Generally, although few people speak the language, it seems to occupy a high status as it is the language of higher education, in the judiciary system, and in diplomatic circles (Schimied, 1986). Abdulaziz (1972) adds that English has important functions, as it is the language of science, technology, international trade, and commerce. Moreover, The Education and Training Policy (1995) contends that the objectives of language teaching in secondary education are to promote the development of competency in linguistic ability and effective communication.

However, for a long time now, students' performance in English language in national examinations has been consistently poor. In 1997 and 1998, for example, the trend indicates that the majority of students, specifically 72.4 percent, $(n=42,176)$ were unable to score a credit pass $(A, B$ or $C)$, and a clear 36.5 percent failed the examination. Table 1 shows clearly the pattern and level of students' performance in English language in 1997 and 1998. 
Table 1. Form Four English Language Examination Results in Percentage 1997 - 1998

\begin{tabular}{|c|c|c|c|c|c|c|c|c|c|c|c|c|}
\hline \multirow{3}{*}{ YEAR } & \multirow{3}{*}{ SEX } & \multicolumn{10}{|c|}{ GRADE } & \multirow[b]{3}{*}{ TOTAL } \\
\hline & & \multicolumn{2}{|c|}{ A } & \multicolumn{2}{|c|}{ B } & \multicolumn{2}{|c|}{ C } & \multicolumn{2}{|c|}{$\mathrm{D}$} & \multicolumn{2}{|c|}{ FAILED } & \\
\hline & & $\mathbf{N}$ & $\%$ & $\mathrm{~N}$ & $\%$ & $\mathrm{~N}$ & $\%$ & $\mathrm{~N}$ & $\%$ & $\mathrm{~N}$ & $\%$ & \\
\hline & F & 85 & 0.5 & 486 & 2.6 & 3266 & 17.5 & 5744 & 30.0 & 9134 & 48.7 & 18,715 \\
\hline \multirow[t]{3}{*}{1997} & $\mathrm{M}$ & 208 & 0.9 & 1270 & 5.5 & 7227 & 31.3 & 7758 & 33.6 & 6626 & 28.7 & 23.089 \\
\hline & Total & 293 & 0.7 & 1756 & 4.2 & 10493 & 25.1 & 13502 & 32.3 & 15760 & 37.7 & 41,804 \\
\hline & F & 56 & 0.3 & 420 & 2.1 & 2879 & 14.6 & 7055 & 35.7 & 9357 & 47.3 & 19,767 \\
\hline \multirow[t]{2}{*}{1998} & M & 114 & 0.5 & 1027 & 4.5 & 6013 & 26.4 & 9453 & 41.5 & 6173 & 27.1 & 22,778 \\
\hline & Total & 170 & 0.4 & 1447 & 3.4 & 8892 & 20.9 & 16508 & 38.8 & 15530 & 36.5 & 42,547 \\
\hline
\end{tabular}

Source: Malekela (1999)

\section{STATEMENT OF THE PROBLEM}

Although English language is taught in Tanzanian schools from the primary school level, the majority of students are performing poorly in national examinations. It is conceivable that this poor performance may be explained by the fact that, learning a foreign language effectively is associated with learners' motives and needs to learn it. Factors such as academic advancement or career aspirations may shape their attitudes towards the language, and hence students' performance.

In this context, this study was designed to investigate the motivational factors for learning English language in the Tanzanian context, and to relate this to students' performance in English language. The study explored the effects of selected background variables especially age, learners' exposure to the English language-learning environment and their perceptions of the factors that motivate them to learn the language on learners' performance in the subject.

The major research tasks were two fold; first, to find out the relationship between students' English language background and their performance in the subject.

- To what extent does students' English language background influence their performance in the subject?

- How does students' use of English determine their performance in the subject?

Second, to find out how students' motivations to learn English language influence their performance in the subject.

- What are the students' motivations in learning English language in secondary schools?

- To what extent do students' motivations to learn English language influence their performance in the subject? 
This study has potential practical relevance in the context of understanding the predispositions of secondary school students to study English language both inside and outside the classroom, in that these factors influence students' perseverance in language such that students will learn the language skills that are relevant to their educational needs and aspirations.

On the other hand, this study is a timely concern given that there is an outcry about the deteriorating standards in both written and spoken English in Tanzania. Apparently, the findings of the study could be significant in an attempt to reverse the trend and improve expression in English and particularly performance in the subject in the Tanzanian secondary school system.

\section{Students' Linguistic Background and Second Language Learning} Language is always a medium of communication in any society. Education on the other hand, is a process of preparing the young generation for future membership in the society (Nyerere, 1968). Education has to do with passing ideas and concepts on the young generation so that they may acquire knowledge that is to be used to bring about development in the society (Qorro, 1997). Education is carried out largely through the medium of language, thus the language is very significant in the education process as it helps learners to precisely express the concepts, ideas, and knowledge being taught hence lead to better performance.

Students' success in learning a second or foreign language depends very much on their linguistic repertoire, that is, their knowledge of the target language they have that will facilitate their effective learning of the language. Additionally, students' language characteristics such as their pre school knowledge of the language, the time they were first exposed to the language, and the frequency of language use seem to be very significant to the second or foreign language learning.

In Tanzania, students in secondary schools reflect a wide range of linguistic background. Roy-Campbell and Qorro (1997) found out that very few secondary school students in the country had English as their first language while the majority, particularly those born outside the urban areas, had a language other than Kiswahili as their first language. In terms of English language performance, studies show that most pupils complete their primary school education with little or no knowledge of English language (Boma, 1980; Mushi, 1989; and Mbowe. 1994), thus the situation persists when they enter secondary school. Clipper and Dodd (1984) observed that the amount of English language secondary school students were exposed to was a more foreign than a medium of education or second language.

However, pupils, who begin to learn and use English language at an early age, that is, before or during primary school, are likely to be more proficient 
in it than their counterparts. Empirical studies done in Tanzania indicated that students' lack of pleasant English proficiency was attributed to their optimal limited use of the language out side the class (Mushi, 1989 and Mbowe, 1994). Therefore, the class seems to be the only place that facilitates learning and acquiring of the language. This state of affairs has resulted to students' little opportunity to practice English language that they learn as a subject at school.

All these reflect the fact that there is a need for learners to be exposed to the language they learn, in this respect English, in terms of practical meaningful use, so as to enhance their learning of the language. Thus, language practices both inside and outside the class is very imperative.

\section{Achievement Motivation and School Performance}

Motivation is a complex phenomenon (Littlewood, 1995). It includes many components such as the individual's drives, curiosity, desire for new experiences and, need for achievement and success. Farrant (1980), restricting the definition in the classroom context, relates motivation to forces that determine how much effort an individual puts into his/her learning.

Recent research has broadened the traditional socio-psychological approaches to motivation in order to increase its educational potentiality. Ames and Archer (1988) focused more on learners' classroom behaviour. They maintain that motivation has an educational and personal dimension in addition the social one. In this way, research on language learning motivation is at an important stage of development to explain learners' performance in the target language.

In language learning, Krashen (1981) identifies two motivational orientations namely: integrative motivation, that is, the desire to be like members of the community that speaks the target language, and instrumental motivation which is the learners' desire to achieve proficiency in a language for practical (utilitarian) reasons. Under the latter perspective, the learner is more interested on how the language s(he) is learning can be a useful tool towards furthering other goals such as gaining a necessary qualification or improving employment prospects (Baker, 1992).

The importance of motivation in learning cannot the underestimated since it contributes much in reinforcing learning among learners. Girad (1972) argues that motivation determines the rate of learning as it influences success or failure through reinforcement. He asserts that an individual will be highly motivated to learn a second or foreign language if he/she expects success or he/she is sure of getting to use the language after learning it.

Bloom (1982).asserted that if learners possess all requisites for a learning task, then it would be possible for them to adequately learn the task provided that they are motivated to do so and if the quality of instruction is appropriate to 
their needs. Supporting this assertion, Ames and Archer (1988) argued that achievement goals among learners determine patterns of motivation which direct how learners think about and engage in different academic activities, such as full participation in the study and increased frequency in learning of the task which in turn results to better performance.

To Oxford and Shearin (1994) motivation facilitates learning as it provides some kind of internal drive that encourages the learner to pursue a course of action. In this way, the learners' success or failure in learning a second or foreign language is thus influenced by their determination. Motivational variables such as language practical values and communication needs determine whether or not learners will avail themselves to the language informal contexts (Krashen, 1981), which in turn encourages them to acquire and communicate more frequently in its medium.

Generally, language learning is unlike the study of other subjects in that the learners have in it very adequate feedback of his/her success or failure to reach the goal. Thus, unless sub goals are clearly defined for her/him, the learner may get discouraged in learning a second or foreign language, which may lead to his/her poor performance in it.

\section{METHOD}

\section{Area of Study}

The study was based on secondary schools in Kilimanjaro region. The selection of the area was prompted by the researcher's familiarity with the area. This consideration was appropriate in the view of the temporary financial constraints that beset the study. Moreover, Kilimanjaro region caters for education of the local people as well as from both urban and rural areas around the country (Omari, 1994). Thus, schools were of varying characteristics and have students from different social and linguistics backgrounds, which were essential variables to explain students' attitudes and motives towards English language learning in relation to their performance in the subject.

\section{Target Population}

The population of this study included secondary school students and teachers in Tanzania. However, the target population included Forms One and Four students and their teachers of English language.

Form One students were included in the study because they had just completed primary education where they were learning all subjects, in the Kiswahili medium, except English language, thus the change to English as the language of instruction in secondary schools was of great importance to explain students' attitudes towards English language and their motives to learn the language. 
Form Four students on the contrary, were involved in the study because at their level, the English language syllabus content for ordinary level was supposed to have been covered, and thus language skills such as speaking, listening, reading and writing had been achieved by the learners. Additionally, Form Four students would have more immediate needs of the language for higher studies or employment, and that would adequately gauge students' attitudes and motives to learn English language.

Teachers of English language were involved in the study, as they were the important input in the teaching-learning process. Their views on students' attitudes and motives for learning English language would be of great importance in the study. Teachers provided information that was useful for analyzing and discussing the findings.

\section{Sample and Sampling Techniques}

The two districts, Moshi urban, which had twelve secondary schools and Moshi rural with forty secondary schools, were selected to represent the urban and rural categories, respectively. Using the school location as a strata, the researcher employed a stratified sampling technique to select six secondary schools for the study, which were; Ashira, Kibosho, Majengo, Mlama, Old Moshi, and Uru Seminary.

The selection of teacher respondents from each school was through the purposive sampling technique, which was utilized to deliberately choose respondents depending on the data intended to be collected (Kothari, 1990). Thus Forms One and Four teachers of English language from each school were included in the study on the merit of their duties.

Students' respondents on the other hand, were selected by randomly picking one stream in each form from each school. Since streaming in Tanzanian secondary schools is not based on ability (Rubagumya, 1993), it was reasoned that whichever stream was picked, provided a fairly representative sample of all students in that form. The number of students in each stream ranged from 27 to 44 . Table 2 shows the composition of the sample by sex.

Table 2: The Composition of the Sample by Sex

\begin{tabular}{lccc|}
\hline CATEGORY & MALE & FEMALE & TOTAL \\
\hline Students & 180 & 184 & 364 \\
Teachers & 10 & 10 & 20 \\
Total & 190 & 194 & 384 \\
\hline
\end{tabular}




\section{Data Collection}

To derive the relevant information for the study, two instruments were used namely: questionnaires and achievement tests. The questionnaire, which Kothari (1990) described as the means of eliciting feelings, beliefs, experiences, or attitudes of some individuals, was used for the study to get first hand information from both students and teachers. While the teachers' questionnaire sought information on the availability and quality of teaching-learning materials in schools, the students' questionnaire consisted of three sections. Section one sought the biographical information of members; section two was made of students' English language background; and section three had items that tapped information on students' motivation to learn English language. In this section respondents were to respond by rating the appropriate response on the four Likert-Scale, ranging from "strongly agree" to "strongly disagree". Scores obtained were correlated with students' performance in the achievement tests.

The achievement tests in both classes were administered to students so as to ascertain their performance in English language. The tests were both curriculum based as they covered the content as stipulated in the respective syllabuses. Both tests consisted of three sections namely: comprehension, structure, and composition. The whole test was marked, by the researcher and two independent teachers of English language, out of 100 points basing on the marking scheme. Scores obtained measured students' performance and were used as dependent variable in the study.

\section{Procedure}

The questionnaire was piloted at Mawenzi secondary school in Kilimanjaro region. This was done so as to achieve the following objectives: First, to find out if any of the items was ambiguous, second, to determine the extent to which the instrument would provide the type of data anticipated, and third, to determine the internal consistency or reliability and the validity of the questionnaire. This was found to be of fairly quality, with the reliability coefficient of 0.87 .

The students' questionnaire and the achievement tests were administered by the researcher with the help of respective teachers of English language of every class in each school. Questionnaires were distributed to each respondent, and achievement tests were administered after the questionnaire was dully filled. As for teachers, questionnaires were distributed to each respondent and time and day for collection were set.

Correlation coefficients were computed so as to show the strength and direction of relationship between variables. Spearman correlation coefficient (rho) was used to study the relationship as stated in the research questions. All statistics were performed using SPSS version 10.0 for window software package. 


\section{RESULTS}

\section{Students' English Language Performance Levels}

Students differed in relation to their mastery of English language as reflected in their scores in the given tests. Table 3 shows Form One results.

Table 3: Form One Performance by Test Sections

\begin{tabular}{lcccccccc}
\hline \multirow{2}{*}{ TEST } & \multicolumn{7}{c}{ PERFORMANCE LEVEL } \\
\hline Section & Maximum & \multicolumn{2}{c}{ Male } & \multicolumn{2}{c}{ Female } & \multicolumn{2}{c}{ Total } \\
\hline \multirow{2}{*}{ Comprehension } & Score & Mean & SD & Mean & SD & Mean & SD \\
Structure & 30 & 15 & 4.5 & 13 & 4.7 & 14 & 4.7 \\
Composition & 35 & 23 & 6.2 & 20 & 5.7 & 22 & 6.2 \\
Whole Test & 35 & 14 & 11.7 & 11 & 5.8 & 12 & 9.1 \\
& 100 & 52 & 13.8 & 44 & 12.2 & 48 & 13.5 \\
\hline
\end{tabular}

Results showed that in Form One, the average scores in the comprehension section was 14 out of 30 , with boys getting a higher mean score than girls, which was 15 and 13, respectively. The performance in the structure section was on the whole; better than other sections, with the mean score of 22 out of 35 , again boys with the mean score of 23 , outperformed girls whose average was 20 . The performance in the composition section yielded the lowest mean of 12 out of 35, with the boys scoring the average of 14 and girls making 11 . The mean score of the test was 48 percent, with boys having a mean score of 52 percent and girls 44 percent. However, the standard deviations, which indicated how students differed in terms of performance, were higher, meaning that there were students who scored higher marks with others having low scores.

In Form Four, the results showed similar trends, with students performing poorly in composition and scoring higher marks in the structure section, the mean scores were 18 out of 35 and 21 out of 35, respectively. In the comprehension, the average score was 16 out of 30 . Interestingly, boys and girls' performance in all sections was equal. Table 4 summarizes the results.

Table 4: Form Four Performance by Test Sections

\begin{tabular}{l|c|cc|cc|cr}
\hline \multirow{2}{*}{ TEST } & \multicolumn{5}{|c|}{ PERFORMANCE LEVEL } \\
\hline \multirow{2}{*}{ Section } & \multirow{2}{*}{$\begin{array}{c}\text { Maximum } \\
\text { Score }\end{array}$} & \multicolumn{2}{|c|}{ Male } & \multicolumn{2}{c|}{ Female } & \multicolumn{2}{c}{ Total } \\
\cline { 3 - 8 } & Mean & SD & Mean & SD & Mean & SD \\
\hline Comprehension & 30 & 16 & 6.3 & 11 & 6.2 & 16 & 6.2 \\
Structure & 35 & 11 & 5.7 & 21 & 4.5 & 21 & 5.2 \\
Composition & 35 & 18 & 6.7 & 18 & 4.2 & 18 & 4.4 \\
Whole Test & 100 & 57 & 21.1 & 53 & 11.0 & 54 & 12.2 \\
\hline
\end{tabular}




\section{Linguistic Background and Performance}

Data on students' English language background was sought so as to ascertain the extent to which this influenced their performance in the subject. Students were asked to indicate the type of primary school they had attended, the class in which they started learning English and the frequency of English language use, both at home and school.

The results indicated that of all students' respondents $(n=450)$, only 6 percent $(n=30)$ attended English medium primary school, while the majority of them, 94 percent $(n=420)$ had their primary school education through the medium of Kiswahili. As for the class when they started learning English language, the majority of them or 80 percent $(n=358)$ showed that they started learning English when they were in standard three. The rest started learning the language much earlier, that is, 5 percent $(n=28)$ in standard One and 15 percent $(n=64)$ in the pre school stage.

When asked how often students used English for communication both at home and school, respondents showed that they used the language most often at school than when they were at home. Table 5 shows that the majority of students or 49 percent $(n=222)$ admitted that they rarely used the language at home, 4 percent $(n=18)$ disclosed that at home, they did not use the language at all. However, 47 percent $(n=187)$ indicated that they used English language at home when communicating with parents, friends and relatives.

At school, the situation was somehow different because the frequency of English language use was reported to be much higher. It was found that almost all students, 84 percent $(n=377)$ used the language at school for communication. The rest of the respondents however, or 16 percent, admitted that they rarely used at school. It was reported that at school, students often had contacts with their teachers as well as amongst themselves through this medium.

Table 5: Students' Rating of their Use of English Language at Home and School

\begin{tabular}{l|r|r|r|r|r|r|r|c}
\hline & \multicolumn{2}{|l|}{ Very often } & \multicolumn{2}{c|}{ Often } & \multicolumn{2}{c|}{ Rarely } & \multicolumn{2}{c}{ Never } \\
\cline { 2 - 10 } & $\mathrm{n}$ & $\%$ & $\mathrm{n}$ & $\%$ & $\mathrm{n}$ & $\%$ & $\mathrm{n}$ & $\%$ \\
\cline { 2 - 10 } English language use at home & 30 & 7 & 180 & 40 & 222 & 49 & 18 & 4 \\
English language use at school & 193 & 43 & 184 & 41 & 73 & 16 & 0 & 0 \\
\hline
\end{tabular}

It was expected that students' performance in English language would correlate positively with their language background variable, which were; the type of primary school attended, and the class at which they started learning English language. Moreover, English language use at home and school was expected to yield positive correlates with students' performance in English language. To test all these, Spearman correlation coefficients were calculated at the significance level of 0.01 . The result showed moderate to higher correlations in the expected direction. Table 6 shows this pattern. 
Table 6: Correlations between Language Environment and Test Scores by Form

\begin{tabular}{l|c|c|c|c|c|}
\hline & Form & Comprehension & Structure & Composition & $\begin{array}{c}\text { Whole } \\
\text { Test }\end{array}$ \\
$\begin{array}{l}\text { Type of primary } \\
\text { school attended }\end{array}$ & I & 0.15 & 0.14 & 0.150 & $23^{* *}$ \\
IV & 0.13 & 0.06 & 0.05 & 0.06 \\
Class started & I & $0.47^{* *}$ & $0.56^{* *}$ & 0.17 & $0.36^{* *}$ \\
learning English & IV & $0.52^{* *}$ & $0.54^{* *}$ & 0.19 & $0.39^{* *}$ \\
English language & I & $0.51^{* *}$ & $0.58^{* *}$ & $0.60^{* *}$ & $0.55^{* *}$ \\
use at home & IV & $0.53^{* *}$ & $0.53^{* *}$ & $0.64^{* *}$ & $0.57^{* *}$ \\
English language & I & $0.86^{* *}$ & $0.87^{* *}$ & $0.92^{* *}$ & $0.88^{* *}$ \\
use at school & IV & $0.74^{* *}$ & $0.85^{* *}$ & $0.93^{* *}$ & $0.83^{* *}$ \\
\hline
\end{tabular}

Key: ${ }^{* *}$ Correlation is significant at 0.01 level

In Form One, the performance in the whole test had positive and significant correlations with the two language background variables, that is, 0.36 for class at which students started learning English language. However, in Form Four, while the first variable had a positive but insignificant correlation with students' performance (0.06), the second variable, that is, the class at which students started learning English language determined their performance in the subject at the secondary school level. This yielded the correlation coefficient of 0.39 .

Moreover, when the performance in the three sections were correlated with students' language background variables, positive correlations were obtained, with the class at which students were exposed to English language being the most important factor that determined students' performance in the subject, and the structure section had higher correlation coefficients than the other sections.

The data also supported the hypothesis that English language use at school; determines greatly students' performance in English language examinations. The results showed that correlation coefficients were highly positive and significant in both variables across all sections as well as the whole test scores. The highest correlates were between English language use at school and students' performance in the composition section, with the correlation coefficient of 0.92 and 0.9 , for Form One and Four, respectively, while the lowest correlates were obtained in the English language use at home with the comprehension section with the coefficients of 0.51 in Form One and 0.53 in Form Four. 


\section{Motivation for Learning English}

The study intended to identify students' motivations to learn English. The motivations were categorized into two orientations as given by Gardner and Lambert (1972), which are: instrumental motivation and integrative motivation.

\section{(a) Integrative Motivations to Learn English Language}

Respondents were provided with items that sought to gauge their motivations to learn English language in secondary schools. These were: To communicate both in and outside the country; To access information from TV, radio, the internet and newspapers; Going anywhere in the world if one knows English language; making friends in and outside the country; and to meet relatives' needs for one to have the knowledge of English language. Table seven summarizes the result.

Table 7: Students' Ratings on the Integrative Motivations to Learn English

\begin{tabular}{l|cc|cc|cc|cc}
\hline & \multicolumn{2}{|c|}{ SA } & \multicolumn{2}{c|}{ A } & \multicolumn{2}{c|}{ D } & \multicolumn{2}{c}{ SD } \\
\cline { 2 - 8 } & $\mathrm{n}$ & $\%$ & $\mathrm{n}$ & $\%$ & $\mathrm{n}$ & $\%$ & $\mathrm{n}$ & $\%$ \\
\hline $\begin{array}{l}\text { Communicating in and outside } \\
\text { the country }\end{array}$ & 341 & 76 & 129 & 29 & 17 & 3 & 4 & 1 \\
$\begin{array}{l}\text { Access to information from } \\
\text { the Media }\end{array}$ & 259 & 58 & 159 & 35 & 25 & 5 & 7 & 2 \\
$\begin{array}{l}\text { Getting anywhere in the world } \\
\text { on English knowledge }\end{array}$ & 240 & 53 & 126 & 28 & 53 & 12 & 31 & 7 \\
$\begin{array}{l}\text { Making friends in and outside } \\
\text { the country }\end{array}$ & 279 & 62 & 130 & 29 & 22 & 5 & 19 & 4 \\
$\begin{array}{l}\text { Relatives want me to have the } \\
\text { knowledge of English }\end{array}$ & 309 & 69 & 109 & 24 & 19 & 4 & 13 & 3 \\
\hline
\end{tabular}

$$
\begin{aligned}
& \text { Key: } S A=\text { Strongly Agree } \quad A=\text { Agree } \\
& S D=\text { Strongly Disagree } D=\text { Disagree }
\end{aligned}
$$

The results confirmed the fact that students were driven by integrative motivations to learn English language. Thus students agreed by 96 percent that they learnt English language in order to communicate with other speakers of the language in and outside the country, while only 4 percent disagreed. Additionally, the majority of respondents, $(n=418)$ or 93 percent, were of the opinion that the knowledge of English language helped them to access information from TV, radio newspapers and the Internet. Another motivational factor was expressed in the statement: "Most of my relatives want me to have a good knowledge of English language". About 93 percent of the respondents supported this. Those who disagreed were only 7 percent. 
The data further showed that 81 percent of the respondents $(n=366)$ shared the view that one can go anywhere in the world if $s($ he) has the knowledge of English language. However, as many as 19 percent $(n=84)$ disagreed. Similarly, the majority of the respondents $(n=409)$ or 91 percent agreed that they learned English language so as to have friends both in and outside the country.

\section{(b) Instrumental Motivations to Learn English Language}

Five items: Reading books written in English; Passing School and national examinations; advancing in other school subjects, advancing for further studies; and getting employment; were provided to respondents so as to elicit instrumental motivations ihat compelled students to learn English language. The result is shown on Table eight.

Table 8: Students' Rating on the Instrumental Motivations to Learn English

\begin{tabular}{l|cc|cc|cc|cc}
\hline & \multicolumn{2}{|c|}{ SA } & \multicolumn{2}{c|}{ A } & \multicolumn{2}{c|}{ D } & \multicolumn{2}{c}{ SD } \\
\cline { 2 - 9 } & $\mathrm{n}$ & $\%$ & $\mathrm{n}$ & $\%$ & $\mathrm{n}$ & $\%$ & $\mathrm{n}$ & $\%$ \\
\hline $\begin{array}{l}\text { Reading books written } \\
\text { in English }\end{array}$ & 341 & 76 & 86 & 19 & 19 & 4 & 4 & 1 \\
$\begin{array}{l}\text { Advancing in other } \\
\text { school subjects }\end{array}$ & 317 & 70 & 124 & 28 & 7 & 1.5 & 2 & 0.5 \\
$\begin{array}{l}\text { Advancing for further } \\
\text { studies }\end{array}$ & 314 & 70 & 121 & 27 & 11 & 2 & 4 & 1 \\
$\begin{array}{l}\text { Pass School and National } \\
\text { Examination }\end{array}$ & 385 & 79 & 92 & 20 & 3 & 1 & 0 & 0 \\
\begin{tabular}{l} 
Getting Employment \\
\hline
\end{tabular} & 216 & 48 & 171 & 38 & 44 & 10 & 19 & 4 \\
\hline
\end{tabular}

$\begin{array}{lll}\text { Key: } & S A=\text { Strongly Agree } & A=\text { Agree } \\ & S D=\text { Strongly Disagree } & D=\text { Disagree }\end{array}$

The results indicated that Tanzanian secondary school students are instrumentally motivated to learn English language, that is, utilitarian values of learning the language are to pass examinations and getting employment through the knowledge of English language. The data revealed that the most important reason for students in secondary schools to learn English was to enable them learn other school subjects. This was shown by 98 percent $(\mathrm{n}=$ 441). English language is the medium through which all subjects except Kiswahili and French are taught. The data also showed that 97 percent of the respondents shared the view that they leaned English because it helped them advance for further studies after the ordinary level. Passing school and national examinations was another motivational factor that made students learn English language. 
Asked whether they learned English in order to read books written in that language, 95 percent of the respondents $(n=427)$ agreed while only 5 percent disagreed. Furthermore, students admitted that they learned English language so that they can get employment after school, as shown by 86 percent of the respondents.

The Relationship between Motives and Performance

An index of students' motives for learning English language was obtained after awarding scores and summing up in the Likert-Scale: "Strongly agree", "agree", "disagree" and "strongly disagree". The students' scores in the achievement test were used as the dependent variable. To test this notion, Spearman correlation coefficient was computed. The results, which are presented in table nine, indicated that there were moderate to high relationship in the expected direction.

Table 9: Correlation between Test Scores and Students' Motivation to Learn English Language

\begin{tabular}{l|l|c|c|c|c}
\hline & Form & Comprehension & Structure & Composition & $\begin{array}{c}\text { Whole } \\
\text { Test }\end{array}$ \\
\cline { 2 - 6 } $\begin{array}{l}\text { Instrumental } \\
\text { Motivation }\end{array}$ & I & $0.47^{* *}$ & $0.48^{* *}$ & $0.33^{* *}$ & $0.49^{* *}$ \\
& IV & $0.45^{* *}$ & $0.49^{* *}$ & $0.42^{* *}$ & $0.67^{* *}$ \\
Integrative & I & $0.43^{* *}$ & $0.48^{* *}$ & $0.33^{* *}$ & $0.44^{* *}$ \\
Motivation & IV & $0.56^{* *}$ & $0.46^{* *}$ & $0.41^{* *}$ & $0.59^{* *}$ \\
Overall & I & $0.21^{* *}$ & $0.27^{* *}$ & $0.30^{* *}$ & $0.31^{* *}$ \\
Motivation & IV & $0.40^{* *}$ & $0.47^{* *}$ & $0.39^{* *}$ & $0.56^{* *}$ \\
\hline
\end{tabular}

Key: ** Correlation is significant at 0.01 level

In Form One, the correlation coefficient was 0.31 . In the two subscales of the motivation variable, that is, instrumental and integrative motivations correlation coefficients were positively significant at 0.49 and 0.44 , respectively. In the over all motivation category, the coefficients were 0.21 for comprehension: 0.27 for structure and 0.30 for composition. The instrumental motivation variable had highest correlation coefficients than all, that is, 0.33 for composition, 0.47 for comprehension and 0.48 for structure. On the other hand, the integrative motivation variable yielded moderate correlation coefficients with test sections at $0.33 ; 043$; and 048 for composition, comprehension and structure; respectively.

In Form Four, results showed that correlation coefficients obtained were very high at 0.59 for integrative motivation; 0.67 for instrumental motivation and 
0.56 for the overall motivation scale. Moreover, when the three sections of the test were correlated with students' responses to the two motivation subset variables, they all yielded positive and significant correlation coefficients. In the instrumental motivation variable, results were 0.42 for composition; 0.45 for comprehension and 0.49 for structure, while the integrative motivation variable had $0.41 ; 0.46$; and 0.56 ; for composition; structure and comprehension; respectively. The overall motivation scale yielded 0.39 for composition; 0.40 for comprehension and 0.47 for structure.

Teachers were asked to indicate factors that influence the learning and teaching of English language in secondary schools. These were their responses.

- Lack of learning material

- Students' poor English language foundation

- Students' lack of practice in spoken and written English

As for problem that teachers face in teaching English language; they mentioned:

- Heavy teaching loads and

- Big number of students in class

\section{DISCUSSION}

It was found that students in Tanzanian secondary schools had varying experiences in terms of encounters with English language when they started their studies at that level, depending much on how they learned and the way they were exposed to the language. However, the type of primary school attended had low correlations with students' scores in the achievement test implying that it had very little influence on students' performance in English language at the secondary school level, it was rather students' hard work in learning as well as their teachers' efforts that determined, to a large extent, students' performance in the subject.

Conversely, in terms of the class in which students started learning English language, the results showed moderate correlations across all test sectors. This implies that the influence of the competence in English language acquired at early stages of learning is significant and this had influence on current students' performance in English language. There were much higher correlations in structure than other sections. This can be explained by the fact that right from early classes, students are taught more language grammar and structure than any other language said such as comprehension and extensive reading, composition or writing skills; and spoken skills. In fact, composition, which was poorly performed, was the most affected area, as it received little attention in terms of learning time, with teachers claiming to have inadequate time for reading and making students' essays. In deed, teachers said that they had very high teaching loads. 
However, from the teachers' perspective, failure to provide writing exercises was caused by over crowded classes. One teacher respondent had this to say: "It is very hard for a teacher to reach every student while teaching because the class is too big. In fact, this is the main reason for not giving regular exercises to students, especially writing skills exercise, which demand a lot of reading students' works.'

Additionally, teachers indicated that a heavy teaching load, which was a result of shortage of teachers of English language to meet the demand of the increased number of students, contributed to a large extent, to the lack of effective teaching among most teachers. Teachers were of the opinion that an increased workload had decreased their readiness to attend individual students academically. Unlike teachers of most other subjects, teachers of English language need to provide and mark students' written work regularly in order to facilitate students' interest in learning it.

As regards English language use at home, the result showed that moderate correlation coefficients with students' performance in the subject. It was revealed that most students hardly used English language in the home environment when communicating with parents, friends and relatives. Consequently this state of affairs hampered students' ability to improve their command of the language. Finocchiaro (1982) firmly argues that second or foreign language learning requires a great deal of exposure and practice. Thus, students' limited exposure to English language in the home environment may affect not only their knowledge of the language, but also their performance in English language as the school subject. It is through practice, that is, frequency use in the language being taught that learners will continuously master the language skills.

In terms of English language use at school, the findings indicated that students conversed through this language most frequently when communicating with their teachers and among themselves. Thus, students were more exposed to English language when they were at school compared to the home environment. Indeed the relationship between students' use of English language at school and their performance in the subject were very high, indicating that regular practice in spoken English was an important prerequisite to their better performance in the subject. The findings were similar to what Mvungi (1982) found in that learners performed better in English language when the bond between stimulus and response was strengthened through regular practice. In this case, learners' frequent use of the language played a role of reinforcing the language skills and knowledge being taught.

It was found out that in an effort to improve students' English knowledge, schools normally inserted regulations that ensured that there was frequent use of the language. In all schools visited, there was a policy of encouraging 
the use of English language in the school premises. It took the form of monitoring the language of students and imposing penalties for speaking a language other than English. Most students admitted that the system was very effective and it helped them to perform better in English language and in other subjects. In all, the system was found to be effective as it aimed at motivating students to use English language so as to equip them with confidence and thus, get a better command of the language.

Teachers noted that such language use practices regular debates, scrabble games, drama, songs and story telling through the medium of English language, helped learners to acquire English language knowledge such as spelling, tenses and verb patterns, which facilitated students' command of English. Additionally, internal school competitions through tests and quizzes as well as frequent exercises, especially in writing skills, could help to sustain students' interests in the use of English language, which in turn would facilitate their better performance in the subject.

Furthermore, teachers stipulated that language teaching is rooted in the process of experience through using the language itself. They maintained that it is the duty of the teacher to extend the range of experience in such a way that students will face new demands for language use, hence facilitate effective performance in both spoken and written aspects of the language. In this way, teachers contribute in a number of ways in helping students acquire the language skills through sustaining interest towards learning English language.

\section{The Nature of Students' Motivation of Learning English}

The most important factors for students in Tanzanian secondary schools to learn English language were both instrumental and integrative in nature. Thus such factors as reacting books written on English, passing school and national examinations, excelling in other school subjects, advancing for further studies and that English will someday be useful in getting employment, acted as incentives to learn the language and formed the basis for instrumental motivation.

Academic achievement was considered to be one of the influencing factors for learning English language. In this way, students' positive motivation to learn the language acted as a determinant factor for effective learning. It influenced success and it helped to further other students' goals such as performing better in school subjects so that they may advance further in the education ladder. One Form One respondent had this to say: "English language helps me and other students pass well examinations... we put much effort to learn it as one day, we will go Form Five up to the University..."

It can be deduced that students' aspirations to pass examinations in English and other school subjects directed their desire to learn the language. In this 
way, English language was perceived mostly as the key to good performance in which students sought in terms of getting higher grades. Thus, those who were not competent in English were often ashamed of themselves and in academic matters, they became introverts.

In another study, Stipek (1996) found that the way performance was evaluated strongly affects students' motivations to learn the task, in which learners will strive to achieve high grades. However, students' learning outcomes especially in learning a language may be hampered if emphasis will be placed on learning the language for the sole purpose of passing school and national examinations. As it has been noted, this emphasis normally takes the form of teaching grammatical structures of the language and neglects other language skills such as comprehension, composition, and the spoken form of the language. It was further found that teachers were worried about how to drill students to obtain high scores on the English paper in both school and national examinations.

Furthermore, the majority of students admitted that English was very vital for employment opportunities. The globalization process, which was associated with foreign investment, had lead to an increased demand of English language. In this case to work in international organizations, tourist hotels, public as well as private sectors, one needed the knowledge of English language. One Form Four student, who was stressing the importance of English language in employment possibilities remarked:"...Additionally, English language help you to communicate with other people in the office during search of employment. Foreign companies in the country now need English....."

It is important to be aware that the trends in the labour market had changed in the country. Unlike in the past, current trends show that there is a big increase in job requiring good communication skills in English and sound knowledge of information technology. It has been a trend now for job seekers to prove their mastery of this language. Thus, most employers require applicants to be competent in both spoken and written English. The youth feared that if they did not know the language, they would not compete fairly in the job market.

The findings further indicated integrative motivation also played part in students' need to learn English language. It was found out that the knowledge of English was required in situations where students might have more opportunities to use the language for various purposes such as making friends and maintaining regular communication with them, traveling or meeting other speakers of English in and outside the country. In this way, the issue for most people in the country has been to be able to communicate in English as the society has made the language very vital for those who want to advance. Many youths also aspired of going abroad; hence the knowledge of English 
was very imperative.

Additionally, the language was needed for accessing information from the mass media. The increased role of English language in the mass media had motivated many students to aspire to learn the language so as to meet global challenges. In Tanzania, for example, there was an increased use of English language in both print and electronic media. This was a response to the free press and the integration of communication with the worldwide network.

An advert of globalization has brought the revolution of information technology in which English is the monopolistic language. These developments inserted pressure among students such that they were encouraged to learn English more as a way of getting to understand the puzzle of life. Thus, without the knowledge of English language, one was likely to be left out and would not be able to access information on current issues happening around the world. Because the current linguistic situation favours the use of English to access information globally, the students were being quite realistic. All Internet cafes in town use English language.

Another motivation for learning English language was an increase in the immediate social needs that required the use of English language. Most students indicated that there were social pressures from parents, relatives and friends that required them to have the knowledge of English language. Students most often are told to be critical of themselves in their work and in life by keeping trying harder to the fullest potential realizing that this can be achieved through interacting with others, English being the language of interaction.

Parents' aspirations of what they anticipated their children to be doing after schooling played a significant role in determining the kind of subjects their children had to learn. Most of the subjects required the knowledge of English language. Thus the community need for English language were very high, and this was reflected in their need to have their children to study through the medium of English from the primary school level and those who were in secondary schools were required to learn the language and master it. This evinced that English language had gained high social acceptance in the community.

The relationship between students' motivation to learn English language and their performance in the subject was found to be strong and positive. This implied that high students' performance was greatly related to their motivation to learn the language. This supported Jackson's (1968) findings that a person who entered a learning context feeling generally satisfied, was likely to learn more successfully. The translation of this argument in the learning of a foreign or second language is simple. Foreign or second language learning requires 
concentration and efforts from learners. To succeed in class therefore, students need to continually work hard while having in mind that there was a utility in learning the language.

It was found out that motivation played an important role in learning English in secondary schools, regardless of which class students studied in. The overall picture concerning secondary school students' motivation towards learning English was very positive as students generally showed a high motivation to learn the language.

From the teachers' perspective, availability of learning and teaching material stimulated students' motivations to learn English language. This in a great deal facilitated the linguistic input in learning the language. In this respect, if teaching and learning material such as audio-visual media were not available, students' motivations to effectively learn English would have not been sustained. Generally, lack of teaching and learning material resulted to teachers resorting to giving students written notes. This observation was in live with Mtana's (1998) findings that schools which had a great number and a wider variety of class readers and other English language books, performed better in English examinations than schools which lacked these learning materials. It is therefore apparent that in a situation in which there is lack of leaning and teaching material, the learning process, and the performance in particular will be affected.

\section{CONCLUSIONS}

It can be concluded that English competency among secondary school students were not as bad as often claimed, and in general, students valued English highly in the Tanzanian education system. Thus, for students to perform better academically, the knowledge of the language of instruction is very vital because through it, learners will be able to express and acquire knowledge and skills, hence achieve higher grades. Students' ability in English language was found to be good with the mean scores around 50 percent in both classes, although there were some variations among students.

Students in Tanzania secondary schools had varying backgrounds in English language. While type of primary school attended was not an important factor that determined students' performance in English at the secondary school level, the time when students are first exposed to English language was very important in language acquisition and learning. This facilitated learners' frequent use of the language in their daily communication needs, which in turn reinforced the taught subject content.

Students had high motivations to learn English language, which provided an effective basis for learning the language. They had both integrative and instrumental motivations focusing on the expected benefits in the language 
such as further studies and achieving high grades in school subjects. In this way, the status of English, which was regarded as a ladder to success both academically and professionally and for wider communication, was considered very important. These high motivations to learn the language were likely to be stable, given the local job market and international communication needs.

\section{RECOMMENDATIONS}

(i) There is a need for improving the teaching of English language in secondary schools capitalizing on strong motivation for learning of the language by teaching the language from the pre-school stage to lay strong foundations of learning the language at later stages.

(ii) Teacher training colleges need to have special programmes of educating teachers (of all subjects) in both spoken and written English to equip them with skills of teaching the language and through the language more effectively.

(iii) Efforts need to be made to ensure that the standard number of 45 students per class is maintained. This will enable teachers to attend effectively 'students' learning needs, the task which is impossible to achieve in large groups.

(iv) Care should be exercised in any attempt to change English as the medium of instruction in secondary schools as students favoured it as the language of instruction. It is important that the choice of the language of instruction should need learners' expectations of the language.

\section{REFERENCES}

Abdulaziz, M.H. (1972) "Tanzania National Policy and the Rise of Swahili Political Culture", In L. Cliff, and J. S. Saul (eds) Socialism in Tanzania, Vol. I, Nairobi:,East Africa Publishing House, pp.32-51.

Ames, C and Archer, J. (1988), "Achievement Goals in the Classroom: Students Learning Strategies and Motivation Processes", Journal of Educational Psychology, Vol. 80, pp. 260 - 267.

Baker, C. (1992), Attitudes and Language. Clevendon: Multilingual Matters.

Beck, R.C. (1978), Motivation Theories and Principles. Eagle woods: Printice Hall.

Bloom, B.S. (1982), Human Characteristics and School Learning. New York: McGraw Hill.

Boma, A.E. (1980), "Factors Affecting Performance in Tanzania Schools" MA Dissertation, University of Dar es Salaam. 
Clipper, C. and Dodd, W. (1984), "Report on the Teaching of English Language and its Use as Medium of Instruction in Tanzania.", The British Council, in Dar es Salaam.

Dornyei, Z. (2000), "Motivation in Action: Towards a Process Oriented Conceptualization of Student Motivation", British Journal of Educational Psychology, Vol. 70, No. 4, pp. 519-538.

Farrant, J.S. (1980), Principles and Practice of Education. London: Longman

Finocchiaro, M. (1982), " Motivation: Its Crucial Role in Language Learning", ERIC Document Reproduction Service No. ED 22330

Gardner R.C. and Tremblay, P.F (1994), "On Motivation, Research Agendas, and Theoretical Frameworks", Modern Language Journal. Vol. 78, pp. 359-368.

Gardner, R.C and Lambert, W. (1972), Attitudes and Motivation in Second Language Learning", Rowley, Newbury House.

Jackson, P. (1968), Life in Classroom, New York, Holt, Renehalt Inc.

Kothari, C.R. (1990), Research Methodology: Methods and Techniques, New York: Wiley.

Krashen, S. (1981), Second Language Acquisition and Second language Learning, Oxford: Oxford University Press.

Littlewood, W. (1995), Foreign and Second Language Learning, Cambridge: Cambridge University Press.

Malekela, G.A. (1999), "Declining Quality of Education in Tanzania: What are we Teachers to Do?", A Valedictory Lecture to Education Graduates, University of Dar es Salaam.

Mbowe, C.C. (1994), "Factors Influencing Lack of Interest in the English Communications Skills Course among Students in Tanzania Technical Training Institutions", MA (Ed) Dissertation. University of Dar es Salaam.

Mtana, N.J. (1998), "An Evaluation of the Impact of ELTSP and $8^{\text {th }}$ IDA Materials on Secondary School Students' Performance in English Language in Tanzania", MA(Linguistics), Dissertation, University of Dar es Salaam.

Mushi, S.L.P. (1989), "A Study of the Adequacy of the Preparation of Diploma English Teachers in Tanzania. The case of Marangu Teachers' College", MA (Ed) Dissertation, University of Dar es Salaam.

Mvungi, M. L. (1982), "Relationship between Performance Instructional Medium and Performance in Selected School Subjects in Tanzania Secondary Schools", Ph.D. thesis, University of Dar es Salaam.

Nyerere, J.K. (1968), Education for Self-Reliance, Oxford University Press, Dar es Salaam: 
Omari, I.M. (1994), Review of Critical Issues in Education in Tanzania, World Bank, Dar es Salaam:

Omari, I.M. and Manase, T.J. (1977), The Tanzania Primary School Leaving Examinations: The Evil They Want to Keep, Department of Education, University of Dar es Salaam.

Oxford R. and Shearin, J. (1994), "Language Learning Motivation: Expanding the Theoretical Framework", Modern Language Journal. Vol. 78, pp. 1228.

Petri, H.L. (1990), Motivation: Theory, Research, and Applications, London: Prentice - Hall.

Pitrich, P.R. and De Groot, E.V. (1990), "Motivational and Self-Regulated Learning Components of Classroom Academic Performance", Journal of Educational Psychology, Vol 82, pp 33-40.

Qorro, M. (1997), "The Role and Place of Language in Education and Society: The Case of Kiswahili and English in Tanzania", Papers in Education and Development, No. 18, pp. 129-143.

Roy-Campbell, Z.M. and Qorro, M.P. (1997), Language Crisis in Tanzania: The Myth of English versus Education, Mkuki na Nyota, Dar es Salaam: .

Rubagumya C.M. (1993), "The Language Values of Tanzania Secondary School Pupils: A Case Study of Dar es Salaam Region", Ph.D. Thesis, Lancaster University.

Rubagumya, C.M. (1999), "Choosing the Language of Instruction in Postcolonial Africa", Papers in Education and Development. No. 20, pp. 125 145.

Schimied, J.J. (1986), English in Tanzania Education. Beyreuth African Studies. Project series No. 15.

Smit, U. and Dalton, C. (2000), "Motivational Patterns in Advanced English as a Foreign Language Pronunciation Learners", International Review of Applied Linguistics in Language Teaching, Vol. 38, No. 4, pp. 229-246.

Solomon, Y and Rogers, C. (2000), "Motivational Patterns in Disaffected School Students: Insights from Pupils Referral Unit Clients", Educational Research Journal, Vol. 27, No. 3. pp. 331-345.

Stipek D. J. (1996), "Motivation and Instruction", In D.C Berlier and R.C Calfee (eds). Handbook for Educational Psychology, New York: Prentice Hall International pp. 85-113.

URT. (1995), Educational and Training Policy, Dar es Salaam: Adult Education Press. 